\title{
Chemotherapy-induced peripheral neuropathy: evidence from genome-wide association studies and replication within multiple myeloma patients
}

Seyed Hamidreza Mahmoudpour ${ }^{1,2,3^{*}}$ (D), Obul Reddy Bandapalli ${ }^{1}$, Miguel Inácio da Silva Filho ${ }^{1}$, Chiara Campo ${ }^{1}$, Kari Hemminki ${ }^{1,4}$, Hartmut Goldschmidt ${ }^{5,6}$, Maximilian Merz ${ }^{5,7}$ and Asta Försti ${ }^{1,4}$

\begin{abstract}
Background: Based on the possible shared mechanisms of chemotherapy-induced peripheral neuropathy (CIPN) for different drugs, we aimed to aggregate results of all previously published genome-wide association studies (GWAS) on CIPN, and to replicate them within a cohort of multiple myeloma (MM) patients.

Methods: Following a systematic literature search, data for CIPN associated single nucleotide polymorphisms (SNPs) with P-values $<10^{-5}$ were extracted; these associations were investigated within a cohort of 983 German MM patients treated with bortezomib, thalidomide or vincristine. Cases were subjects that developed CIPN grade 2-4 while controls developed no or sub-clinical CIPN. Logistic regression with additive model was used.

Results: In total, 9 GWASs were identified from the literature on CIPN caused by different drugs (4 paclitaxel, 2 bortezomib, 1 vincristine, 1 docetaxel, and 1 oxaliplatin). Data were extracted for 526 SNPs in 109 loci. One hundred fourty-eight patients in our study population were CIPN cases (102/646 bortezomib, 17/63 thalidomide and 29/274 vincristine). In total, 13 SNPs in 9 loci were replicated in our population ( $p$-value< 0.05 ). The four smallest $P$-values relevant to the nerve function were 0.0006 for rs8014839 (close to the FBXO33 gene), 0.004 for rs4618330 (close to the INTU gene), 0.006 for rs 1903216 (close to the BCL6 gene) and 0.03 for rs4687753 (close to the IL17RB gene).

Conclusions: Replicated SNPs provide clues of the molecular mechanism of CIPN and can be strong candidates for further research aiming to predict the risk of CIPN in clinical practice, particularly rs8014839, rs4618330, rs1903216, and rs4687753, which showed relevance to the function of nervous system.
\end{abstract}

Keywords: GWAS, Chemotherapy, Neuropathy, Multiple myeloma, Adverse drug reaction

\section{Background}

Chemotherapy-induced peripheral neuropathy (CIPN) is a disabling common adverse drug reaction of several chemotherapeutic agents including platinum compounds, taxanes, vinca alkaloids, proteasome inhibitors and thalidomide. The reported incidence of CIPN is ranging from $12.1 \%$ up to

\footnotetext{
* Correspondence: mahmoudpour@uni-mainz.de

'Division of Molecular Genetic Epidemiology, German cancer research center (DKFZ), Im Neuenheimer Feld 580, DE-69120 Heidelberg, Germany

${ }^{2}$ Institute for Medical Biostatistics, Epidemiology, and Informatics (IMBEI),

Department of Biometry and Bioinformatics, University Medical Centre of the Johannes Gutenberg University, Mainz, Germany

Full list of author information is available at the end of the article
}

over $90 \%$ of patients undergoing treatment with various antineoplastic agents [1]. CIPN not only restricts the treatment (dose reductions, delay or cessation of therapy) but also significantly influences the patient's quality of life after treatment. The 5-years survival rate for people diagnosed with cancer of any site was $66.9 \%$ in the US in 2013 [2]. It is therefore important to predict and prevent CIPN for a better quality of life in the growing number of cancer survivors.

A number of candidate gene approach studies have shown different genetic predictors of CIPN [3-5]. However in general, most of the candidate gene approach studies have been difficult to replicate and their results

(c) The Author(s). 2018 Open Access This article is distributed under the terms of the Creative Commons Attribution 4.0 International License (http://creativecommons.org/licenses/by/4.0/), which permits unrestricted use, distribution, and reproduction in any medium, provided you give appropriate credit to the original author(s) and the source, provide a link to the Creative Commons license, and indicate if changes were made. The Creative Commons Public Domain Dedication waiver (http://creativecommons.org/publicdomain/zero/1.0/) applies to the data made available in this article, unless otherwise stated. 
should be interpreted with extreme caution [6]. On the other hand, recent robust genome-wide association studies (GWASs), mainly focussing on individual chemotherapeutic agents, have introduced several genetic markers to predict the risk of CIPN. However, many of those associations have not been replicated yet in an independent population or within patients treated with other chemotherapeutic agents. Hypothesizing on shared mechanisms of CIPN for different medications, we aimed to replicate the associations of all previously published GWASs on CIPN within a cohort of newly diagnosed multiple myeloma (MM) patients treated with either bortezomib, vincristine or thalidomide.

\section{Methods}

\section{Literature search}

In order to extract data from all previously published GWASs on CIPN, a systematic literature search was conducted within the PubMed central database until December 2016 for the English language references. To maximize the search coverage, medical subject heading $(\mathrm{MeSH})$ terms for the "genome-wide association study" and "chemotherapy" and "neuropathy" were included. Title and abstract of the retrieved references were screened manually to include only original human studies that investigated the association of CIPN with genetic variations on the whole-genome level. Animal studies, review articles, editorials and abstracts of conferences were excluded. Furthermore, all references of the included studies or review studies were also assessed for additional published articles not included in the original search or not indexed in PubMed. Full texts of all included studies were retrieved via the library of German cancer research center (DKFZ). The following information was extracted from the full text or via direct contact with the authors of included studies: publication year, source of the clinical data (study design), ethical approval statement, sample size (number of cases and controls), chemotherapy medication that caused CIPN, cancer site, genotyping methods, ethnicity of patients and for the replication, all
SNPs associated at the significance level of the $P$-values $<10^{-5}$ were retrieved. If no SNP reached below this threshold, only the most significantly associated SNP reported in the paper was selected. All non-SNP genetic variations were excluded for replication. The effect sizes were extracted from the paper either as odds ratios (ORs), hazard ratios (HRs) or beta coefficients. Chromosomal positions, reference allele and alternate alleles were extracted from database of Single Nucleotide Polymorphisms (dbSNP) [7].

\section{Patient sample, genotyping and data analyses}

The study population comprised patients selected from a previously performed GWAS in Germany on 1082 MM cases, recruited through the German-Speaking Myeloma Multicenter Group (GMMG), coordinated by the University Clinic Heidelberg. About $85 \%$ of patients were registered in 3 clinical trials (HD3, HD4 and MM5) [8-10]; about 15\% were recruited outside clinical trials (Table 1). In summary, the patients received one of the following therapy regimens as an induction therapy followed by maintenance therapy and autologous stem-cell transplantation: a) bortezomib, doxorubicin, and dexamethasone (PAD), b) vincristine, doxorubicin, and dexamethasone (VAD), c) thalidomide, doxorubicin, and dexamethasone (TAD). From 646 patients who were treated with bortezomib, 480 patients $(74.3 \%)$, were treated intravenously (IV) and 154 patients (23.8\%) subcutaneously (SC). For 12 patients (1.8\%), the route of administration was changed from IV to SC during the treatment. For all the patients, neuropathy was evaluated before the start of every therapy cycle, after the induction therapy, and before the stem-cell transplantation. The latest version of Common Terminology Criteria for Adverse Events (CTCAE) was used to grade the CIPN (version 2.0 for HD3, version 3.0 for HD4, version 4.0 for MM5, and various versions for patients outside the trials). Patients were excluded from trials, if they had clinically relevant pre-existing neuropathy; in case of subclinical pre-existing

Table 1 General characteristics of study population

\begin{tabular}{|c|c|c|c|c|c|c|c|}
\hline \multicolumn{2}{|c|}{ Characteristics } & \multicolumn{3}{|c|}{ CIPN Cases (148) } & \multicolumn{3}{|c|}{ Controls (835) } \\
\hline \multicolumn{2}{|c|}{ Mean age } & \multicolumn{3}{|l|}{57.48} & \multicolumn{3}{|l|}{57.30} \\
\hline \multicolumn{2}{|c|}{ Gender male \% } & \multicolumn{3}{|l|}{$86(58 \%)$} & \multicolumn{3}{|l|}{493 (59\%) } \\
\hline \multirow{3}{*}{\multicolumn{2}{|c|}{ History of neuropathy }} & \multicolumn{3}{|l|}{$21(14.2 \%)$} & \multicolumn{3}{|l|}{$30(3.6 \%)$} \\
\hline & & \multicolumn{3}{|l|}{ Medication } & \multicolumn{3}{|l|}{ Medication } \\
\hline & & Bortezomib & Vincristine & Thalidomide & Bortezomib & Vincristine & Thalidomide \\
\hline \multirow[t]{4}{*}{ Study } & HD3 & - & 4 & 6 & - & 53 & 40 \\
\hline & HD4 & 28 & 15 & - & 116 & 132 & - \\
\hline & MM5 & 47 & - & - & 394 & - & - \\
\hline & NTP & 27 & 10 & 11 & 34 & 60 & 6 \\
\hline \multicolumn{2}{|l|}{ Total } & 102 (68.9\%) & $29(19.6 \%)$ & 17 (11.5\%) & $544(65.2 \%)$ & 245 (29.3\%) & $46(5.5 \%)$ \\
\hline
\end{tabular}

CIPN chemotherapy-induced peripheral neuropathy, NTP non-trial patients 
neuropathy, the history of neuropathy was recorded. Sample and clinical data collection from patients was done with informed consent and with the relevant ethical review board approval in accordance with the Declaration of Helsinki (ethical committee numbers: L-119/2001, L-222/2004, and AFmu-119/2010 from the University Clinic Heidelberg [11]. For the replication of associations from the previous GWASs on CIPN, in the present study only the patients treated with either bortezomib, vincristine or thalidomide were taken into account [12]: 983 European newly diagnosed MM patients, out of whom 148 were CIPN cases of grade 2-4 (102/646 treated with bortezomib, 29/274 treated with vincristine and 17/63 treated with thalidomide).

Genotyping was completed using Illumina Human OmniExpress arrays, in accordance to the manufacturer's protocols (Illumina, San Diego, USA). Standardized quality control measures were implemented, prior to any association analysis. Samples in which less than 95\% of SNPs were successfully genotyped were excluded. Principal component analysis was utilized to assess and correct population stratification and unanticipated relatedness. SNPs with call rates of less than $95 \%$ or with minor allele frequency (MAF) of less than $1 \%$ or with deviation from Hardy-Weinberg equilibrium with $P<10^{-5}$ in controls were excluded from the analyses. To increase the genome coverage, imputation based on the 1000 Genomes data was performed using IMPUTEv2 for SNPs not present in the Illumina arrays. Imputed SNPs with an information metric $<0.30$ or MAF $<1 \%$ were excluded [13]. Estimates of odds ratios (ORs), corresponding 95\% confidence intervals (CIs) and P-values were obtained from logistic regression models assuming an additive genetic model to assess the association of selected SNPs with the CIPN. For the replicated SNPs on the nominal level of significance $(p<0.05)$, alleles were aligned with the literature reported alleles, in a way that the same risk alleles were considered for both replication and the original publication. In case of discordance between risk alleles, the SNP was not considered to be replicated. The strongest signal in each locus was further investigated.

\section{In silico functional analyses}

To investigate the influence of the replicated SNPs, their regulatory nature and the possible functional effects of the SNPs or their associated SNPs $\left(r^{2} \geq 0.8\right)$, computational predictions were performed using the HaploReg v4.1 tool (www.broadinstitute.org/mammals/haploreg), which contains data from the Roadmap Epigenomics and ENCODE projects, sequence conservation data across mammals, the effect of SNPs on regulatory motifs, and the effect of SNPs on expression from eQTL studies. For eQTL hits, the most relevant tissues were presented together with the correlated gene and reported $P$-value. The RefSeq data and GENCODE data were used for the gene annotation [14]. The UCSC genome browser home (https://genome.ucsc.edu/) was used that gives a rapid and detailed access to any region of the genome and the tool RegulomeDB (http://regulomedb.org/) was used to identify DNA features and regulatory elements that contain the coordinate of the SNP [15].

\section{Results}

After applying the inclusion/exclusion criteria for the literature search, 9 GWASs were identified on CIPN (Fig. 1). All the included studies stated their ethical approval to conduct the study from relevant authorized ethic committees. Paclitaxel-induced neuropathy was the most common investigated CIPN with 4 studies [16-19], followed by 2 GWASs on bortezomib-induced neuropathy [20, 21]. Vincristine, docetaxel and oxaliplatin-induced neuropathy, each had been studied once [22-24]. Table 2 presents the details of all included studies. There were 2 studies within MM patients, 2 studies in breast cancer patients and 1 study each in prostate cancer, colon cancer and acute lymphoblastic leukemia (ALL) patients. Two studies out of 9 did not specify the cancer site. Almost all GWASs were within the adult population except the one on vincristine-induced neuropathy in children with ALL. This study was also the only included study that meta-analysed GWAS from 2 patient populations. For our study, the most significantly associated SNPs from the meta-analysis $\left(p\right.$-value $\left.<10^{-5}\right)$ were selected for the replication. The number of included genetic variants from this study was the highest among all 9 studies (458 SNPs out of 526 included SNPs in total) [22]. The sample size of included studies ranged from 96 patients to 1357 patients. The smallest study was the one on oxaliplatin-induced neuropathy in colon cancer patients. It was also the only one that did not reported any SNP reaching the significance level of $10^{-5}$, therefore the most significantly associated SNP was selected from this study as reported in the paper [24]. The level of significance ( $P$-values) was extracted for 526 SNPs in 109 loci that met the inclusion criteria for the replication; In each locus the most significantly associated SNP from the literature is highlighted (Additional file 1).

All selected SNPs were investigated in a population of 983 MM patients out of which 148 subjects developed the clinically relevant peripheral neuropathy grade 2 or higher. The general characteristics of included patients are presented in Table 1.

In total 9 loci out of 109 selected loci were replicated in the present study population at the nominal significance level $(p$-value $<0.05)$, however, the strongest signals in the relevant loci reached lower $p$-values (Table 3$)$. Eight of those loci were replicated from one study that investigated the vincristine-induced neuropathy in children with ALL and 2 other loci were replicated from 2 independent studies on paclitaxel-induced neuropathy in patients with breast cancer. SNPs of these 2 loci were directly genotyped 


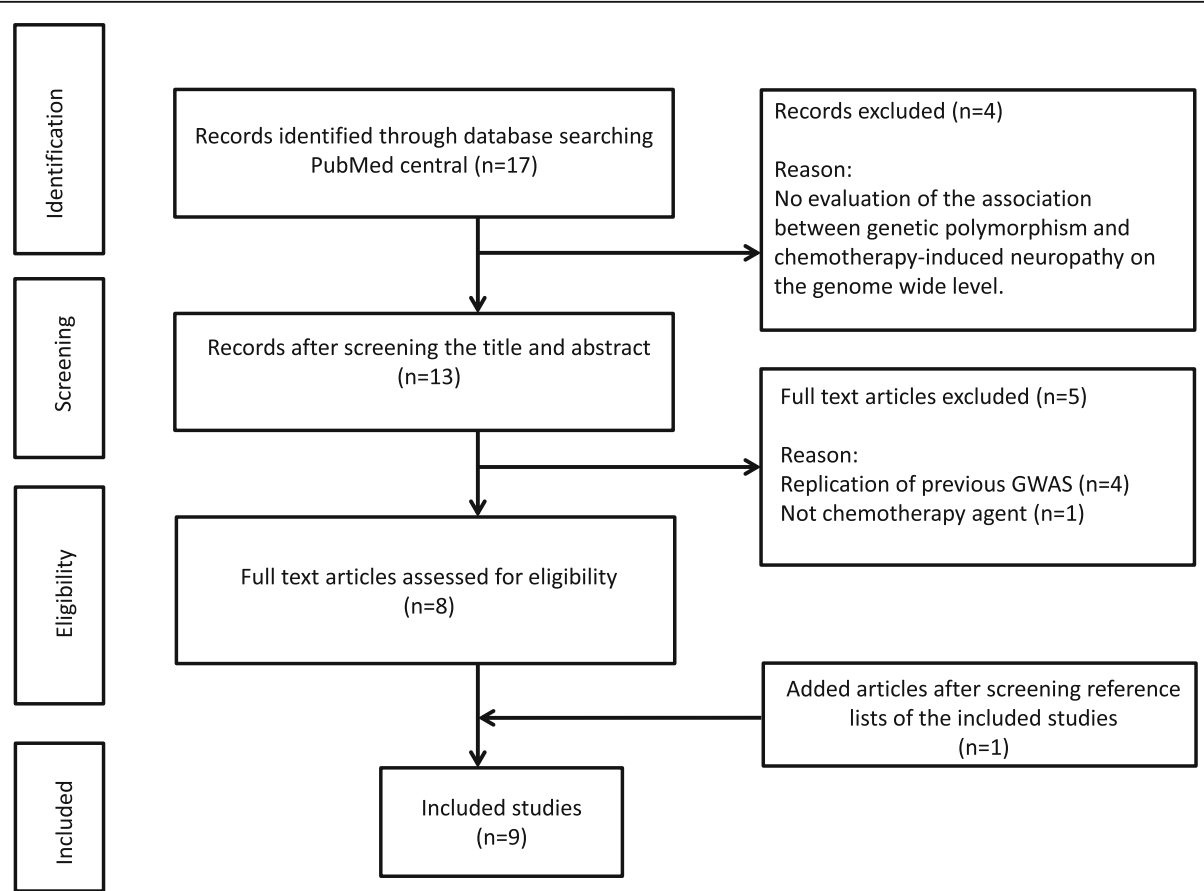

Fig. 1 Flowchart of literature search and study selection in four phases. The figure illustrates the reasons for excluding studies

SNPs and he other 8 replicated loci contained imputed SNPs, however in these loci, there was a genotyped SNP in high linkage disequilibrium (LD) with the imputed one. Table 3 shows the details of the replicated SNP in each locus with its effect size and $p$-value both from the original study and the replication. The strongest signal in each locus from the current study is also presented together with the pairwise LD indicator of $\left(\mathrm{r}^{2}\right)$.

\section{Discussion}

Out of 526 included SNPs in 109 loci, retrieved from 9 independent published GWAS on CIPN, 13 SNPs in 9

Table 2 The details of all included studies

\begin{tabular}{|c|c|c|c|c|c|c|c|}
\hline Reference & Year & $\begin{array}{l}\text { Sample size } \\
\text { case/controls }\end{array}$ & Ethnicity & $\begin{array}{l}\text { Chemotherapy } \\
\text { agent }\end{array}$ & $\begin{array}{l}\text { Source } \\
\text { of data }\end{array}$ & Genotyping & Cancer site \\
\hline Magrangeas & 2016 & $155 / 314$ & European & Bortezomib & $\mathrm{RCT}$ & SNP 6.0 Affymetrix arrays & Multiple myeloma \\
\hline García-Sanz & 2016 & $33 / 139$ & NA & $\begin{array}{l}\text { Bortezomib and/ } \\
\text { or thalidomide }\end{array}$ & $\mathrm{RCT}$ & $\begin{array}{l}\text { Axiom Exome Genotyping } \\
\text { array (Affymetrix) }\end{array}$ & Multiple myeloma \\
\hline Hertz & 2016 & $50 / 566$ & Caucasian & Docetaxel & $\mathrm{RCT}$ & $\begin{array}{l}\text { HumanHap610-Quad } \\
\text { Genotyping BeadChip } \\
\text { (Illumina) }\end{array}$ & Prostate cancer \\
\hline Komatsu & 2015 & $24 / 121$ & Asian & Paclitaxel & $\begin{array}{l}\text { Cohort } \\
\text { study }\end{array}$ & $\begin{array}{l}\text { Illumina Omni-Express } \\
\text { BeadChip }\end{array}$ & Cancer (NS) \\
\hline Schneider & 2015 & $576 / 781$ & European & Paclitaxel & $\mathrm{RCT}$ & $\begin{array}{l}\text { HumanOmni1-Quad } \\
\text { array (Illumina) }\end{array}$ & Breast cancer \\
\hline Diouf & 2015 & $86 / 235$ & $\begin{array}{l}\text { Mixed } \\
\text { population }\end{array}$ & Vincristine & $\mathrm{RCT}$ & $\begin{array}{l}\text { Affymetrix GeneChip } \\
\text { Human Mapping } 500 \mathrm{~K} \text { array } \\
532,552 \text { SNPs) or the } \\
\text { SNP } 6.0 \text { array }(906,600 \text { SNPs) } \\
\text { (Affymetrix) }\end{array}$ & $\begin{array}{l}\text { Acute lymphoblastic } \\
\text { leukemia (ALL) }\end{array}$ \\
\hline Leandro-García & 2013 & $\begin{array}{l}144 \\
\text { Cox } \\
\text { regression }\end{array}$ & European & Paclitaxel & $\begin{array}{l}\text { Cohort } \\
\text { study }\end{array}$ & $\begin{array}{l}\text { Infinium BeadChip Human } \\
\text { 660WQuad assay } \\
\text { (Illumina) }\end{array}$ & Cancer (NS) \\
\hline Baldwin & 2012 & $\begin{array}{l}855 \\
\text { cox } \\
\text { regression }\end{array}$ & European & Paclitaxel & $\mathrm{RCT}$ & $\begin{array}{l}\text { HumanHap610-Quad } \\
\text { Genotyping BeadChip } \\
\text { (Illumina) }\end{array}$ & Breast cancer \\
\hline Won & 2011 & $39 / 57$ & Asian & Oxaliplatin & $\begin{array}{l}\text { Cohort } \\
\text { study }\end{array}$ & $\begin{array}{l}\text { Affymetrix Genome-Wide } \\
\text { Human SNP Array } 6.0\end{array}$ & Colon cancer \\
\hline
\end{tabular}


Table 3 Details of the replicated loci both from published studies, replication cohort and strongest signal in the region

\begin{tabular}{|c|c|c|c|c|c|c|c|c|c|c|c|}
\hline \multirow[t]{2}{*}{ Reference } & \multirow[t]{2}{*}{ Locus } & \multirow{2}{*}{$\begin{array}{l}\text { Published } \\
\text { SNP }\end{array}$} & \multirow{2}{*}{$\begin{array}{l}\text { Strongest } \\
\text { signal in the } \\
\text { locus } \\
\text { (current study) }\end{array}$} & \multirow{2}{*}{$\begin{array}{l}\text { Position } \\
\text { (hg38) }\end{array}$} & \multirow{2}{*}{$\begin{array}{l}\text { Risk } \\
\text { allele }\end{array}$} & \multicolumn{3}{|l|}{ Published studies } & \multicolumn{3}{|l|}{ Replication } \\
\hline & & & & & & Effect size (OR/HR) & $P$-value & Medication & $\begin{array}{l}\text { Association } \\
\text { OR }\end{array}$ & $P$-value & $\begin{array}{l}\text { Imputation } \\
\text { Info }\end{array}$ \\
\hline \multirow[t]{2}{*}{ Diouf } & $14 q 21.1$ & rs8014839 & & $39,374,915$ & G & 3.63 & $5.1 \times 10^{-6}$ & Vincristine & 1.55 & 0.0006 & 0.99 \\
\hline & & & rs $8014839^{a}$ & $39,374,915$ & G & & - & - & NA & NA & NA \\
\hline \multirow[t]{2}{*}{ Diouf } & $4 q 28.1$ & rs4618330 & & $126,757,231$ & $A$ & 0.47 & $6.4 \times 10^{-6}$ & Vincristine & 0.7 & 0.004 & 0.98 \\
\hline & & & rs $28742896^{c}$ & $127,678,685$ & A & & - & - & 0.6 & 0.0001 & 0.99 \\
\hline \multirow[t]{2}{*}{ Baldwin } & $3 q 27.3$ & rs1903216 & & $187,911,715$ & A & 1.59 & $5.6 \times 10^{-6}$ & Paclitaxel & 1.4 & 0.006 & 1 \\
\hline & & & rs $2611620^{c}$ & $187,826,512$ & A & & - & - & 1.69 & $5.6 \times 10^{-5}$ & 0.98 \\
\hline \multirow[t]{2}{*}{ Diouf } & $3 p 14.2$ & rs35558909 & & $60,933,303$ & G & 3.17 & $4.3 \times 10^{-7}$ & Vincristine & 1.36 & 0.01 & 0.98 \\
\hline & & & rs $2121845^{a}$ & $60,922,227$ & A & & - & - & 1.76 & 0.01 & 1 \\
\hline \multirow[t]{2}{*}{ Diouf } & $3 p 21.1$ & rs4687753 & & $53,861,434$ & A & 4.49 & $6.2 \times 10^{-6}$ & Vincristine & 1.32 & 0.03 & 0.99 \\
\hline & & & rs9840079 & $53,858,614$ & T & & - & - & 1.39 & 0.007 & 0.99 \\
\hline \multirow[t]{2}{*}{ Diouf } & $8 q 24.12$ & rs7817522 & & $120,028,312$ & T & 4.21 & $3.1 \times 10^{-6}$ & Vincristine & 1.3 & 0.03 & 0.99 \\
\hline & & & rs $17822044^{a}$ & $119,997,585$ & G & & - & - & 1.35 & 0.02 & 1 \\
\hline \multirow[t]{2}{*}{ Schneider } & $15 q 21.3$ & rs2062640 & & $54,737,776$ & G & 2.01 & $7.9 \times 10^{-6}$ & Paclitaxel & 1.42 & 0.04 & 1 \\
\hline & & & $\operatorname{rs} 2695677^{c}$ & $54,799,953$ & C & & - & - & 1.96 & 0.0003 & 0.98 \\
\hline \multirow[t]{2}{*}{ Diouf } & $2 q 33.3$ & rs11694118 & & $208,077,000$ & A & 0.18 & $8.8 \times 10^{-6}$ & Vincristine & 0.75 & 0.04 & 0.96 \\
\hline & & & $\mathrm{rs} 17538082^{\mathrm{a}}$ & $208,060,995$ & T & & - & - & 0.73 & 0.03 & 1 \\
\hline \multirow[t]{2}{*}{ Diouf } & $5 q 23.2$ & rs10070183 & & $124,521,298$ & C & 0.43 & $2.8 \times 10^{-6}$ & Vincristine & 0.77 & 0.04 & 0.95 \\
\hline & & & rs $10478625^{b}$ & $124,527,954$ & T & & - & - & 0.71 & 0.009 & 1 \\
\hline
\end{tabular}

Chr Chromosome, SNP Single nucleotide polymorphism, OR Odds ratio, HR Hazard ratio, NA: not applicable

${ }^{a} r^{2} \geq 0.8,{ }^{b} r^{2} \geq 0.6,{ }^{c} r^{2} \geq 0.4$ ( $r^{2}$ : The linkage disequilibrium metrics between the SNPs), Imputation Info: the score ranging between 0 and 1 which is the indicator of the certainty of imputation for each SNP

loci were replicated on the nominal level of significance of $P<0.05$ in our study within 983 newly diagnosed MM patients treated with chemotherapy. This was in completion of our previous work [25]. All replicated loci were from 3 relatively large GWASs with the study population of 1357,855 and 321 cancer patients, respectively [16, 19, 22]. The involvement of some of the replicated variants in relevant tissues of the nervous system is potentially an indicator of a true association:

In Table 4, the most relevant results are presented from the computational predictions for potential functionality of the replicated loci, performed using the HaploRegv4.1.

The 14q21.1 locus contains 2 replicated SNPs (rs8014839 and rs9806038). rs8014839 is the most significantly replicated SNP in this region, covering several genes including FBXO33 (F-box protein 33), CTAGE5 (cutaneous T-cell lymphoma-associated antigen, family member 5), TRAPPC6B (trafficking protein particle complex 6B), PNN (pinin, desmosome associated protein), and MIA2 (melanoma inhibitory activity 2). This variant is annotated with histone mark enrichment in several tissues, including the brain. There were $4 \mathrm{eQTL}$ targets reported in the blood, including CTAGE5 at $p$-value $=4.68 \times 10^{-54}, \quad$ TRAPPC6B at $p$-value $=2.80 \times$
$10^{-43}, P N N$ at $p$-value $=3.74 \times 10^{-4}$ and $F B X O 33$ at $p$-value $=4.19 \times 10^{-4}$ [26]. FBXO33 is hypothesised to have function in phosphorylation-dependent ubiquitination and affecting the serum level of inflammatory cytokines [27]. In a recent GWAS it has been shown that the $F B X O 33$ is associated with the attention deficiency hyperactivity disorder (ADHD) as a neurodevelopmental disease. In that study, the authors showed that the variant alleles were associated with decreased FBXO33 expression in lymphoblastoid cell lines and with reduced frontal grey matter volume [28]. The strongest eQTL target of rs8014839, CTAGE5 together with FBXO33 has been associated on a genome-wide level with an optic neuropathy (glaucoma) in animals as one of the leading causes of blindness [29]. Additionally CTAGE5 has an important role in cell membrane transport which is relevant to the function of nervous system [30]. The other strong eQTL target, TRAPPC6B plays a role in vesicle transport which could be important in synaptic nervous system [31]. This evidence indicates that the genetic variants which cause differences in development of the nervous system may lead to variation in neuronal sensitivity, including susceptibility to CIPN, however, functional studies are crucial to reveal the role of these variants in the central nervous system development. 


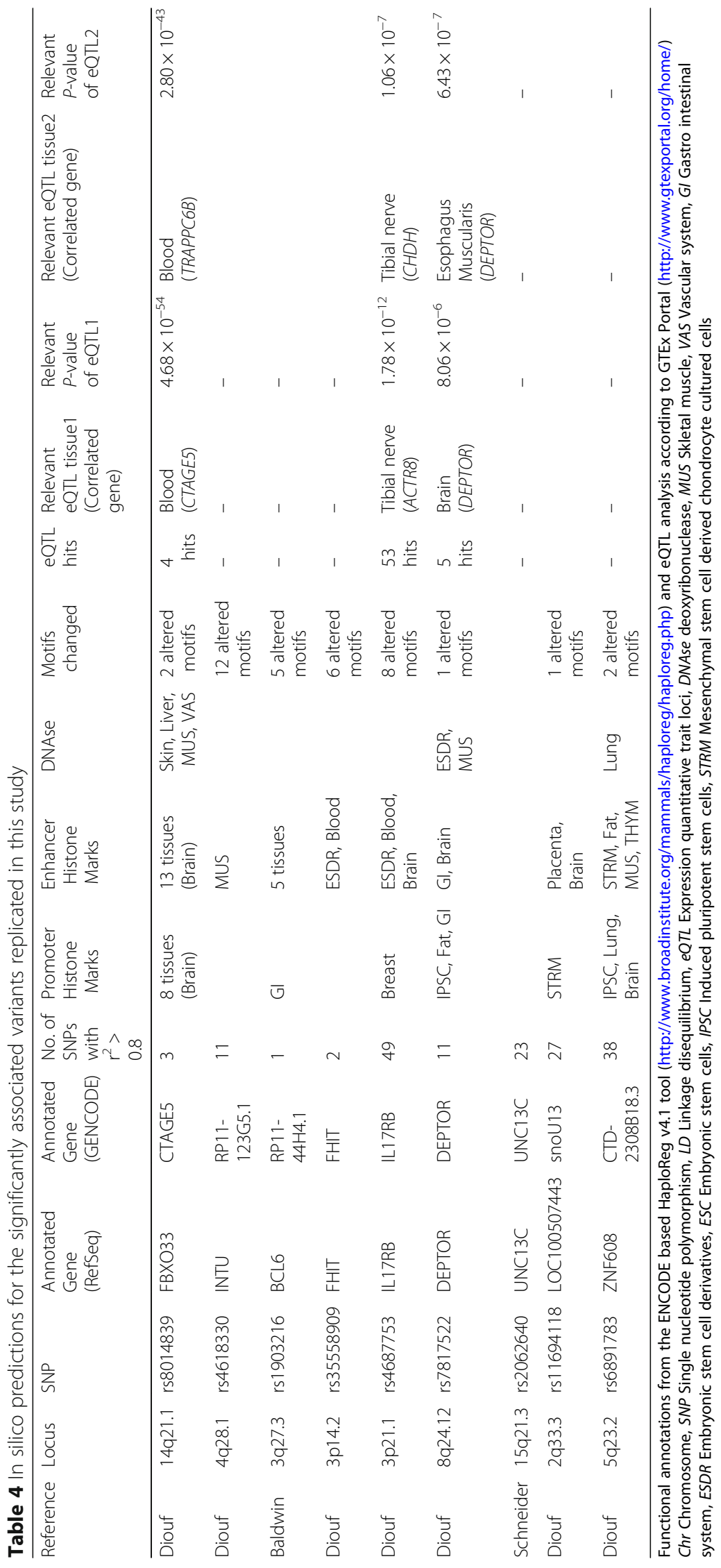


The rs4618330 in 4q28.1 which maps to $876 \mathrm{~kb} 5^{\prime}$ of the INTU (inturned planar cell polarity protein) gene, is associated with 12 motif changes including 8 motif changes in a group of $F O X$ transcription factor family genes [32] and according to the RegulomeDB it is also likely to affect their binding. Although none of the 12 SNPs in the high LD region were reported to function as an eQTL, changes in the FOX binding sites could potentially explain the involvement of the SNPs in the neuropathy because previous studies have shown a role of the FOXA genes in regulating the maintenance of dopaminergic function of neurons, particularly in the embryonic stages [33]. Additionally, FOXJ1 is a significant transcription factor in the central nervous and reproductive systems and overexpression of FOXJ1 has been reported to be highly associated with colon cancer stage and its outcome $[34,35]$. Motif changes for the FOX transcription factor family genes were observed also in other replicated loci in our study within 3p21.1 (rs4687753) and 5q23.2 (rs6891783) [36].

On chromosome 3 , there are 4 replicated loci and rs1903216 in 3q27.3 is the most significantly associated variant among them that maps $166 \mathrm{~kb} 5^{\prime}$ to the $B C L 6$ (B-cell Lymphoma 6) gene and it is one of the key SNPs associated with the CIPN because this SNP is the only one among 9 replicated loci which has previously been replicated both in European and African American populations [16]. However, after that 2 studies have failed to replicate this association. One of them is a small study with only 119 patient treated with paclitaxel out of whom 46 had developed neuropathy [4]. The other one is a larger study with1303 breast cancer patients treated with paclitaxel [36]. The population of this latter study was slightly different from the original GWAS both in distribution of menopausal status (as an age indicator) and HER2 (human epidermal growth factor receptor 2) status while in several study populations the association between age and CIPN has been reported [19, 37, 38]. Therefore, a part of unsuccessful replication could be explained by the interaction between the effect of age and genetic variants. More importantly, the paclitaxel administration intervals were different in these two studies. In the discovery GWAS only patients with biweekly regimen were included [16], while in the small replication study patients had weekly regimen [4] and in the larger replication, at least half of the included patients had therapy every 3 weeks [36]; this longer interval is shown in the other studies to decrease the incidence of neuropathy by around 10\% [39] which could partially explain the unsuccessful replication as well. The $B C L 6$ gene encodes one of the transcription factor proteins which is associated with several lymphomas, such as diffuse large B-cell lymphoma, Hodgkin lymphoma and chronic lymphocytic leukaemia trough program regulation of the germinal centre B cell [40], but its role in the nervous system is not clear yet. The
HaploReg analyses showed enhancer histone mark enrichment in several tissues. It is also related to 5 motif changes, among them $B C L \_$disc6 [32].

3 p21.1 is the other key replicated region which is covering the genes IL17RB (Interleukin 17 receptor B), CACNA1D (calcium voltage-gated channel subunit alpha1 D), $C H D H$ (choline dehydrogenase), ACTR8 (arp8 actin-related protein 8 homolog) and SELK (selenoprotein K). The replicated SNP, rs4687753, in this region is in a high LD $\left(\mathrm{r}^{2}>0.8\right)$ with 49 other variants based on the HaploReg analyses. Fifty-three eQTL hits are related to this variant, the most relevant ones are in nerve tissues targeting ACTR8 at $p$-value $=1.78 \times 10^{-12}, \mathrm{CHDH}$ at $p$-value $=1.06 \times 10^{-7}, I L 17 R B$ at $p$-value $=6.2 \times 10^{-7}$ and SELK at $p$-value $=8.03 \times 10^{-6} . A C T R 8$ and IL17RB are eQTL targets in brain as well at $p$-value of $3.49 \times 10^{-9}$ and $1.49 \times 10^{-7}$, respectively [41]. The role of ACTR8 in transcriptional regulation and DNA repair has been shown previously [42]. Furthermore, there are 8 motif changes associated with this variant including the Foxa_disc4 and $P O U 3 F 2$, the latter one resulting in transcription factor binding site change based on the RegulomeDB data [43]. The effect of this variation on regulating the expression of genes particularly in the nervous system, makes it plausible to contribute to CIPN; this strongly suggests further functional research on the variant.

To the best of our knowledge, this study is the first genetic association study that tries to aggregate results from all GWASs on CIPN and replicate them in an independent and relatively large population. Since we used the data from clinical trials, the quality of phenotype evaluation was high standard. The restricted power of this replication is acknowledged, although the number of included patients was the highest in comparison to all the included GWAS except one of them [19]. Furthermore, when assuming that the 109 tested loci are independent and using the Bonferroni correction for multiple testing $(P=0.05 / 109=0.0004)$, only 3 out of the 9 replicated loci $(4 q 28.1,3 q 27.3,15 q 21.3)$ would survive, which can be considered another limitation of this study. However, the assumption in the Bonferroni correction is that each test has a sufficient statistical power to be successful [44]. This is not the case here as many tests are underpowered and the application of the correction to 109 tests is not appropriate. All the replicated loci were from the three relatively large studies but in addition to the small sample size of other previous studies, there might be other reasons for unsuccessful replication: the grade of CIPN in our study for cases was considered to be two or higher while for example Hertz et al. considered grade three or higher in their study including relatively large number of patients [23]. While the majority of patients in our study were treated with bortezomib, we could not replicate 
the findings from two previous GWAS on bortezomib, probably due to differences in the route of administration of the drug: compared to the previous GWAS, in which IV administration was used, $25 \%$ of the patients in our population had the SC administration and this can modify the risk of CIPN [45].

From the clinical point of view, this study provides additional support for the involvement of genetic variation in CIPN. However, the combined effects of the replicated loci as a genetic risk score needs to be further investigated in an independent population, and the current evidence is not enough to have an immediate impact on clinical practice.

\section{Conclusions}

We replicated several SNPs in 9 loci, previously reported to be associated with CIPN in published GWASs. These findings provide further clue to conduct molecular studies on the effect of those variants on CIPN and to get new insights for better understanding the mechanism of CIPN such as hypersensitivity of nerves that may occur during the nervous system development or the overexpression of proteins involving in the membrane ion exchange procedures and vesicle transport. Additionally, the findings provide evidence that 4 relevant SNPs (rs8014839, rs4618330, rs1903216, and rs4687753) could be promising candidates for predicting the risk of CIPN in the future.

\section{Additional file}

Additional file 1: Eligible SNPS from literature for the replication. The information extracted for 526 SNPs in 109 loci that met the inclusion criteria for the replication; In each locus the most significantly associated SNP from the literature is highlighted. (XLSX $62 \mathrm{~kb}$ )

\section{Abbreviations \\ ADHD: Attention deficiency hyperactive disorder; ALL: Acute lymphoblastic leukemia; Cl: Confidence intervals; CIPN: Chemotherapy-induced peripheral neuropathy; GWAS: genome-wide association studies; HR: Hazard ratio; LD: Linkage disequilibrium; MAF: Minor allele frequency; MeSH: Medical subject heading; MM: Multiple myeloma; OR: Odds ratio; SNP: Single nucleotide polymorphism}

\section{Funding}

This work was supported by the German Cancer Aid, the Harald Huppert Foundations, and the German Federal Ministry of Education and Research [eMed, Cliommics 01ZX1309B]. The funders had no role in study design, data collection, analysis and interpretation of data, and in writing the manuscript.

\section{Availability of data and materials}

The datasets generated and/or analysed during the current study are not publicly available due to the institutional data protection agreement but are available from the corresponding author on reasonable request.

\section{Authors' contributions}

SHM, AF, and $\mathrm{KH}$ designed the study. CC, MM, KH, HG, AF, and MID contributed to data acquisition. MM, HG had access to all clinical data. SHM, KH, HG, AF, and MID had access to all raw data. SHM, MM, CC, ORB and MID contributed to the data preparation, quality control and analyses, and checked the results. SHM and ORB drafted the initial report. All authors contributed to the data interpretation, critically revised the manuscript, and approved the version to be published.

\section{Ethics approval and consent to participate}

Sample and clinical data collection from patients was done with the written informed consent and with the relevant ethical review board approval in accordance with the Declaration of Helsinki. (Ethical committee numbers: L-119/2001, L-222/2004, and AFmu-119/2010 from university hospital Heidelberg.

\section{Consent for publication}

Not applicable.

\section{Competing interests}

The authors declare that they have no competing interests.

\section{Publisher's Note}

Springer Nature remains neutral with regard to jurisdictional claims in published maps and institutional affiliations.

\section{Author details}

${ }^{1}$ Division of Molecular Genetic Epidemiology, German cancer research center (DKFZ), Im Neuenheimer Feld 580, DE-69120 Heidelberg, Germany. ${ }^{2}$ Institute for Medical Biostatistics, Epidemiology, and Informatics (IMBEI), Department of Biometry and Bioinformatics, University Medical Centre of the Johannes Gutenberg University, Mainz, Germany. ${ }^{3}$ Center for Thrombosis and Hemostasis (CTH), University Medical Centre of the Johannes Gutenberg University, Mainz, Germany. ${ }^{4}$ Center for Primary Health Care Research, Lund University, Malmo, Sweden. ${ }^{5}$ Department of Internal Medicine V, University of Heidelberg, Heidelberg, Germany. ${ }^{6}$ National Centre of Tumor Diseases, Heidelberg, Germany. ${ }^{7}$ Department of Radiology, German cancer research center (DKFZ), Heidelberg, Germany.

Received: 5 January 2018 Accepted: 7 August 2018

Published online: 15 August 2018

References

1. Seretny M, Currie GL, Sena ES, Ramnarine S, Grant R, MacLeod MR, Colvin LA, Fallon M. Incidence, prevalence, and predictors of chemotherapyinduced peripheral neuropathy: a systematic review and meta-analysis. Pain. 2014;155(12):2461-70

2. Brewer JR, Morrison G, Dolan ME, Fleming GF. Chemotherapy-induced peripheral neuropathy: current status and progress. Gynecol Oncol. 2016;140(1):176-83.

3. Johnson C, Pankratz VS, Velazquez Al, Aakre JA, Loprinzi CL, Staff NP, Windebank AJ, Yang P. Candidate pathway-based genetic association study of platinum and platinum-taxane related toxicity in a cohort of primary lung cancer patients. J Neurol Sci. 2015:349(1-2):124-8.

4. Boora GK, Kanwar R, Kulkarni AA, Abyzov A, Sloan J, Ruddy KJ, Banck MS, Loprinzi $\mathrm{CL}$, Beutler AS. Testing of candidate single nucleotide variants associated with paclitaxel neuropathy in the trial NCCTG N08C1 (alliance). Cancer Med. 2016;5(4):631-9.

5. Campo C, Da Silva Filho MI, Weinhold N, Goldschmidt H, Hemminki K, Merz M, Forsti A. Genetic susceptibility to Bortezomib-induced peripheral Neuroropathy: replication of the reported candidate susceptibility loci. Neurochem Res. 2017;42(3):925-31.

6. Hirschhorn JN, Lohmueller K, Byrne E, Hirschhorn K. A comprehensive review of genetic association studies. Genet Med. 2002:4(2):45-61.

7. Sherry ST, Ward MH, Kholodov M, Baker J, Phan L, Smigielski EM, Sirotkin K. dbSNP: the NCBI database of genetic variation. Nucleic Acids Res. 2001; 29(1):308-11.

8. Sonneveld P, Schmidt-Wolf IG, van der Holt B, El Jarari L, Bertsch U, Salwender H, Zweegman S, Vellenga E, Broyl A, Blau IW, et al. Bortezomib induction and maintenance treatment in patients with newly diagnosed multiple myeloma: results of the randomized phase III HOVON-65/GMMGHD4 trial. J Clin Oncol. 2012:30(24):2946-55.

9. Goldschmidt H, Sonneveld P, Cremer FW, van der Holt B, Westveer P, Breitkreutz I, Benner A, Glasmacher A, Schmidt-Wolf IG, Martin H, et al. Joint HOVON-50/GMMG-HD3 randomized trial on the effect of thalidomide as part of a high-dose therapy regimen and as maintenance treatment for newly diagnosed myeloma patients. Ann Hematol. 2003;82(10):654-9.

10. Mai EK, Bertsch U, Durig J, Kunz C, Haenel M, Blau IW, Munder M, Jauch A Schurich B, Hielscher T, et al. Phase III trial of bortezomib, cyclophosphamide and 
dexamethasone (VCD) versus bortezomib, doxorubicin and dexamethasone (PAd) in newly diagnosed myeloma. Leukemia. 2015;29(8):1721-9.

11. Chubb D, Weinhold N, Broderick P, Chen B, Johnson DC, Forsti A, Vijayakrishnan J, Migliorini G, Dobbins SE, Holroyd A, et al. Common variation at 3q26.2, 6p21.33, 17p11.2 and 22q13.1 influences multiple myeloma risk. Nat Genet. 2013:45(10):1221-5.

12. Moreau P, San Miguel J, Sonneveld P, Mateos MV, Zamagni E, Avet-Loiseau H, Hajek R, Dimopoulos MA, Ludwig H, Einsele $H$, et al. Multiple myeloma: ESMO clinical practice guidelines for diagnosis, treatment and followupdagger. Ann Oncol. 2017;28(suppl_4):iv52-61.

13. Howie BN, Donnelly P, Marchini J. A flexible and accurate genotype imputation method for the next generation of genome-wide association studies. PLoS Genet. 2009;5(6):e1000529.

14. Ward LD, Kellis M. HaploReg: a resource for exploring chromatin states, conservation, and regulatory motif alterations within sets of genetically linked variants. Nucleic Acids Res. 2012;40(Database issue):D930-4.

15. Boyle AP, Hong EL, Hariharan M, Cheng Y, Schaub MA, Kasowski M, Karczewski KJ, Park J, Hitz BC, Weng S, et al. Annotation of functional variation in personal genomes using RegulomeDB. Genome Res. 2012;22(9):1790-7.

16. Baldwin RM, Owzar K, Zembutsu H, Chhibber A, Kubo M, Jiang C, Watson D, Eclov RJ, Mefford J, McLeod HL, et al. A genome-wide association study identifies novel loci for paclitaxel-induced sensory peripheral neuropathy in CALGB 40101. Clin Cancer Res. 2012;18(18):5099-109.

17. Komatsu M, Wheeler HE, Chung S, Low SK, Wing C, Delaney SM, Gorsic LK, Takahashi A, Kubo M, Kroetz DL, et al. Pharmacoethnicity in paclitaxel-induced sensory peripheral neuropathy. Clin Cancer Res. 2015;21(19):4337-46.

18. Leandro-Garcia $L$, Inglada-Perez L, Pita G, Hjerpe E, Leskela S, Jara C, Mielgo X, Gonzalez-Neira A, Robledo M, Avall-Lundqvist E, et al. Genome-wide association study identifies ephrin type a receptors implicated in paclitaxel induced peripheral sensory neuropathy. J Med Genet. 2013;50(9):599-605.

19. Schneider BP, Li L, Radovich M, Shen F, Miller KD, Flockhart DA, Jiang G, Vance G, Gardner L, Vatta M, et al. Genome-wide association studies for Taxane-induced peripheral neuropathy in ECOG-5103 and ECOG-1199. Clin Cancer Res. 2015;21(22):5082-91.

20. Garcia-Sanz R, Corchete LA, Alcoceba M, Chillon MC, Jimenez C, Prieto I, Garcia-Alvarez M, Puig N, Rapado I, Barrio S, et al. Prediction of peripheral neuropathy in multiple myeloma patients receiving bortezomib and thalidomide: a genetic study based on a single nucleotide polymorphism array. Hematol Oncol. 2017;35(4):746-51.

21. Magrangeas F, Kuiper R, Avet-Loiseau H, Gouraud W, Guerin-Charbonnel C, Ferrer L, Aussem A, Elghazel H, Suhard J, Der Sakissian H, et al. A genomewide association study identifies a novel locus for Bortezomib-induced peripheral neuropathy in European patients with multiple myeloma. Clin Cancer Res. 2016;22(17):4350-5.

22. Diouf B, Crews KR, Lew G, Pei D, Cheng C, Bao J, Zheng JJ, Yang W, Fan Y, Wheeler $\mathrm{HE}$, et al. Association of an inherited genetic variant with vincristine-related peripheral neuropathy in children with acute lymphoblastic leukemia. JAMA. 2015;313(8):815-23.

23. Hertz DL, Owzar K, Lessans S, Wing C, Jiang C, Kelly WK, Patel J, Halabi S, Furukawa Y, Wheeler HE, et al. Pharmacogenetic discovery in CALGB (alliance) 90401 and mechanistic validation of a VAC14 polymorphism that increases risk of docetaxel-induced neuropathy. Clin Cancer Res. 2016;22(19):4890-900.

24. Won HH, Lee J, Park JO, Park YS, Lim HY, Kang WK, Kim JW, Lee SY, Park SH. Polymorphic markers associated with severe oxaliplatin-induced, chronic peripheral neuropathy in colon cancer patients. Cancer. 2012;1 18(11):2828-36.

25. Mahmoudpour SH, Campo C, Da Silva Filho MI, Hemminki K, Goldschmidt H, Merz M, Försti A. Chemotherapy-induced peripheral neuropathy: replication of the results from genome wide association studies within multiple myeloma patients. Pharmacoepidemiol Drug Saf. 2017;26(Suppl. 2):275-6.

26. Westra HJ, Peters MJ, Esko T, Yaghootkar H, Schurmann C, Kettunen J, Christiansen MW, Fairfax BP, Schramm K, Powell JE, et al. Systematic identification of trans eQTLs as putative drivers of known disease associations. Nat Genet. 2013;45(10):1238-43.

27. Weathington NM, Sznajder JI, Mallampalli RK. The emerging role of the ubiquitin proteasome in pulmonary biology and disease. Am J Respir Crit Care Med. 2013;188(5):530-7.

28. Sanchez-Mora C, Ramos-Quiroga JA, Bosch R, Corrales M, Garcia-Martinez I, Nogueira M, Pagerols M, Palomar G, Richarte V, Vidal R, et al. Case-control genome-wide association study of persistent attention-deficit hyperactivity disorder identifies FBXO33 as a novel susceptibility gene for the disorder. Neuropsychopharmacology. 2015;40(4):915-26.
29. Ahonen SJ, Pietila E, Mellersh CS, Tiira K, Hansen L, Johnson GS, Lohi H. Genome-wide association study identifies a novel canine glaucoma locus. PLoS One. 2013;8(8):e70903.

30. Saito K, Yamashiro K, Ichikawa Y, Erlmann P, Kontani K, Malhotra V, Katada T. CTAGE5 mediates collagen secretion through interaction with TANGO1 at endoplasmic reticulum exit sites. Mol Biol Cell. 2011;22(13):2301-8.

31. Kummel D, Muller JJ, Roske Y, Misselwitz R, Bussow K, Heinemann U. The structure of the TRAPP subunit TPC6 suggests a model for a TRAPP subcomplex. EMBO Rep. 2005;6(8):787-93.

32. Kheradpour P, Kellis M. Systematic discovery and characterization of regulatory motifs in ENCODE TF binding experiments. Nucleic Acids Res. 2014;42(5):2976-87.

33. Stott SR, Metzakopian E, Lin W, Kaestner KH, Hen R, Ang SL. Foxa1 and foxa2 are required for the maintenance of dopaminergic properties in ventral midbrain neurons at late embryonic stages. J Neurosci. 2013;33(18): 8022-34.

34. Liu K, Fan J, Wu J. Forkhead box protein J1 (FOXJ1) is overexpressed in colorectal Cancer and promotes nuclear translocation of beta-catenin in SW620 cells. Med Sci Monit. 2017;23:856-66.

35. Zhu P, Piao Y, Dong $X$, Jin Z. Forkhead box J1 expression is upregulated and correlated with prognosis in patients with clear cell renal cell carcinoma. Oncol Lett. 2015;10(3):1487-94.

36. Abraham JE, Guo Q, Dorling L, Tyrer J, Ingle S, Hardy R, Vallier AL, Hiller L, Burns $R$, Jones $L$, et al. Replication of genetic polymorphisms reported to be associated with taxane-related sensory neuropathy in patients with early breast cancer treated with paclitaxel. Clin Cancer Res. 2014:20(9):2466-75.

37. Dolan ME, El Charif O, Wheeler HE, Gamazon ER, Ardeshir-Rouhani-Fard S, Monahan P, Feldman DR, Hamilton R, Vaughn DJ, Beard C, et al. Clinical and genome-wide analysis of cisplatin-induced peripheral neuropathy in survivors of adult-onset Cancer. Clin Cancer Res. 2017;23(19):5757-68.

38. Hershman DL, Till C, Wright JD, Awad D, Ramsey SD, Barlow WE, Minasian LM, Unger J. Comorbidities and risk of chemotherapy-induced peripheral neuropathy among participants 65 years or older in southwest oncology group clinical trials. J Clin Oncol. 2016;34(25):3014-22.

39. Chan JK, Brady MF, Penson RT, Huang H, Birrer MJ, Walker UL, DiSilvestro PA, Rubin SC, Martin LP, Davidson SA, et al. Weekly vs. Every-3-week paclitaxel and carboplatin for ovarian Cancer. N Engl J Med. 2016;374(8):738-48.

40. Hatzi K, Melnick A. Breaking bad in the germinal center: how deregulation of BCL6 contributes to lymphomagenesis. Trends Mol Med. 2014;20(6):343-52.

41. Consortium GT. Human genomics. The genotype-tissue expression (GTEx) pilot analysis: multitissue gene regulation in humans. Science. 2015; 348(6235):648-60.

42. Osakabe A, Takahashi Y, Murakami H, Otawa K, Tachiwana H, Oma Y, Nishijima H, Shibahara KI, Kurumizaka H, Harata M. DNA binding properties of the actin-related protein Arp8 and its role in DNA repair. PLoS One. 2014; 9(10):e108354.

43. Matys V, Kel-Margoulis OV, Fricke E, Liebich I, Land S, Barre-Dirrie A, Reuter I, Chekmenev D, Krull M, Hornischer K, et al. TRANSFAC and its module TRANSCompel: transcriptional gene regulation in eukaryotes. Nucleic Acids Res. 2006;34(Database issue):D108-10.

44. Nakagawa S. A farewell to Bonferroni: the problems of low statistical power and publication bias. Behavioral Ecol. 2004;15(6):1044-5.

45. Moreau P, Pylypenko H, Grosicki S, Karamanesht I, Leleu X, Grishunina M, Rekhtman G, Masliak Z, Robak T, Shubina A, et al. Subcutaneous versus intravenous administration of bortezomib in patients with relapsed multiple myeloma: a randomised, phase 3, non-inferiority study. Lancet Oncol. 2011; 12(5):431-40.

\section{Ready to submit your research? Choose BMC and benefit from:}

- fast, convenient online submission

- thorough peer review by experienced researchers in your field

- rapid publication on acceptance

- support for research data, including large and complex data types

- gold Open Access which fosters wider collaboration and increased citations

- maximum visibility for your research: over $100 \mathrm{M}$ website views per year

At BMC, research is always in progress.

Learn more biomedcentral.com/submissions 